\title{
Cu(I)/Amino Acid Catalyzed Coupling Reactions of Aryl Halides and Nucleophiles: Applications in Large-scale Production
}

\author{
Dawei $\mathrm{Ma}^{*}$ and Yongwen Jiang
}

\begin{abstract}
Amino acids can be used as ligands to promote Ullmann-type coupling reactions. This review briefly discusses how L-proline, 4-hydroxy-L-proline and $\mathrm{N}, \mathrm{N}$-dimethylglycine can serve as the ideal ligands for coppercatalyzed coupling of aryl halides with different nucleophiles. Seven examples of applications of copper/amino acid catalyzed reactions in large-scale preparations are described.
\end{abstract}

Keywords: Copper-catalyzed coupling reactions $\cdot$ L-Proline $\cdot$ Ullmann-type coupling reactions

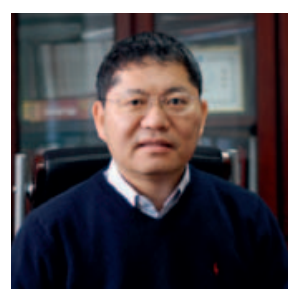

Dawei Ma received his Ph.D. in 1989 from Shanghai Institute of Organic Chemistry (SIOC), and did his postdoctoral studies at the University of Pittsburgh and Mayo Clinic. He returned to SIOC in 1994, and was appointed as research professor in 1995. He is presently the deputy director of SIOC and an associate editor of Journal of Organic Chemistry. His research interests currently focus on the development of new synthetic methodologies, the total synthesis of complex natural products and their SAR and action mode studies, as well as the discovery of small modulators for target proteins and special biological processes.

\section{Introduction}

Since their discovery more than 100 years ago, Ullmann-type coupling reactions have become a typical and inexpensive method for preparing aryl amines, biaryl ethers, and $\mathrm{N}$-aryl heterocycles that are important compounds for developing pharmaceuticals and materials. However, a significant drawback of these reactions is the requirement of a high reaction temperature, which greatly limits its scope of application. In recent years, we have witnessed great progress in solving this problem, which is highly dependent on using selected $\mathrm{N}, \mathrm{N}-, \mathrm{N}, \mathrm{O}$ - and $\mathrm{O}, \mathrm{O}$ bidentate ligands. ${ }^{[1]}$ In the presence of these ligands, the reaction temperatures for copper-catalyzed coupling between aryl halides and some nucleophiles could be greatly decreased. ${ }^{[1]}$ These newly developed coupling methods have found extensive application in synthesis of natural products and designed functional molecules. More importantly, some of these new catalytic systems have been proven to be reliable in large scale preparation. Because of the limited space, in this brief review, we only focus on introducing the reactions catalyzed by $\mathrm{Cu}(\mathrm{I}) / \mathrm{amino}$ acid.

\section{Cross-coupling Reactions Catalyzed by $\mathrm{Cu}(1) / a m i n o$ acid}

The accelerating effect for the Ullmann reaction induced by amino acids was discovered in 1998. During an attempt to assemble enantiopure $\mathrm{N}$-aryl amino acids via coupling aryl halides with enantiopure $\alpha$-amino acids under the assistance of metal complexes, we found that $\mathrm{CuI}$ could serve as an ideal catalyst for this transformation, leading to formation of $\mathrm{N}$-aryl amino acids at $80-90{ }^{\circ} \mathrm{C}$ (Scheme 1).[2] This result clearly indicated that $\alpha$-amino acids could serve as the ligands to promote the Ullmann aryl amination reaction.

Further investigations revealed that amino acids could also promote the coupling of aryl halides with amines, and L-proline was found to be a better ligand for this reaction. ${ }^{[3,4]}$ In most cases, reactions proceeded smoothly at $60-90{ }^{\circ} \mathrm{C}$ to afford the aryl amination products (Scheme 2). However, the coupling partners were limited to aryl iodides, aryl bromides, primary amines and acyclic amines, while aryl chlorides and acyclic secondary amines gave poor conversion under these conditions.

$\mathrm{CuI} / \mathrm{L}$-proline catalyzed coupling of aryl iodides with ammonia took place to produce primary arylamines under the assistance of $\mathrm{Cs}_{2} \mathrm{CO}_{3}$ in DMSO at $50{ }^{\circ} \mathrm{C}$.
${ }^{*}$ Correspondence: Prof. D. Ma

State Key Laboratory of Bioorganic and Natural Products Chemistry

Shanghai Institute of Organic Chemistry

Chinese Academy of Sciences

345 LingLing Road

Shanghai 200032, China

E-mail: madw@sioc.ac.cn







Aryl bromides were found to give poor conversions under these conditions. ${ }^{[5]}$ However, changing the ligand from L-proline to 4-hydroxy-L-proline could solve this problem (Scheme 3). Both electron-rich and electron-deficient aryl bromides were applicable to afford the corresponding coupling products with good yields. ${ }^{[6]}$ The combination of $\mathrm{CuI}$ and 4-hydroxy-L-proline was also able to catalyze the coupling of $N$-Boc hydrazine with both aryl bromides and aryl iodides to give $N$-aryl hydrazides. ${ }^{[6]}$

Under catalysis by $\mathrm{CuI} / \mathrm{L}$-proline, a number of $N$-containing heterocycles were able to couple with aryl iodides
Scheme 4. Cul/ L-proline-catalyzed coupling of aryl halides and $\mathrm{N}$-containing

heterocycles.

Scheme 2. Cul/ L-proline-catalyzed halides and primary amines.

Scheme 3. Cul/ L-proline-catalyzed coupling of aryl halides with ammonia and $N$-Boc hydrazine. coupling of aryl pyrazoles.

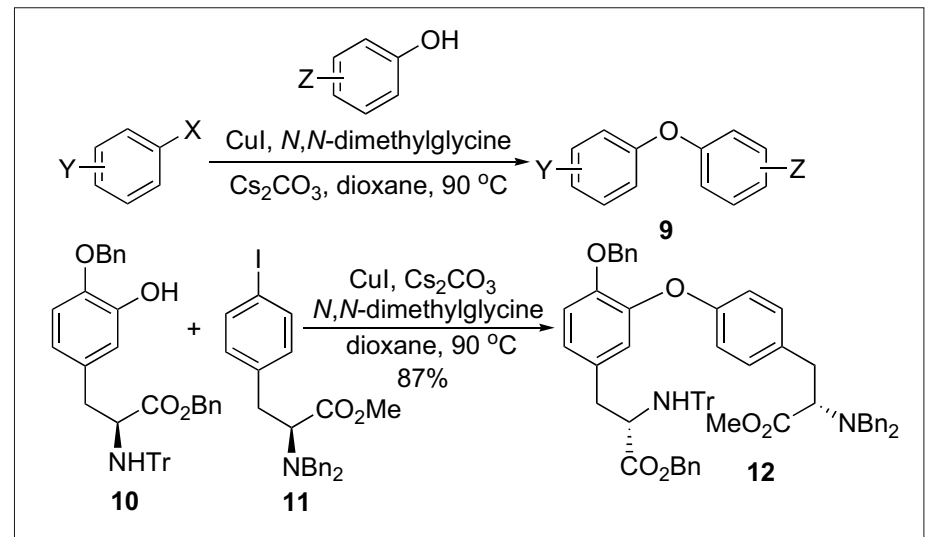

Scheme 5. Cul/ $N, N$-dimethylglycine-catalyzed biaryl ethyl formation from aryl halides and phenols.
5). Noteworthy is that, under these conditions, coupling between L-tyrosinederived phenol 8 and L-phenylalaninederived iodide $\mathbf{9}$ proceeded well to afford biaryl ether $\mathbf{1 0}$ with $87 \%$ yield, thereby providing a facile method for synthesizing amino ester embodied biaryl ethers that are useful building blocks for natural product synthesis. ${ }^{[9]}$ Using trityl and benzyl to protect the amine moiety was essential to prevent the racemization of the amino ester parts.

When 2-halotrifluoroacetanilides 13 were utilized as the coupling partners, $\mathrm{CuI} /$ $\mathrm{N}, \mathrm{N}$-dimethylglycine catalyzed biaryl ether synthesis occurred at room temperature (Scheme 6), indicating that there exists a strong ortho-substituent effect caused by an ortho-amide group. ${ }^{[10]}$ Taking the advantage of this effect, we could carry out coupling of 2-haloacetanilides $\mathbf{1 5}$ with primary amines at room temperature to $50{ }^{\circ} \mathrm{C}$. The resultant aryl amination products, upon treatment with acetic acid, could be transferred into 1,2-disubstituted benzimidazoles 16.[11] This one-pot, two-step transformation provides a powerful approach to assess this class of pharmaceutically important heterocycles with great diversity.

Aryl sulfones could be assembled by $\mathrm{CuI} / \mathrm{L}$-proline catalyzed coupling of aryl halides with sulfinic acid salts (Scheme 7). Two sulfinic acid salts, sodium methanesulfinate and sodium benzenesulfinate, were examined for this transformation. The coupling conditions they required were slightly different. For sodium methanesulfinate, coupling reaction with aryl iodides took place at $80{ }^{\circ} \mathrm{C}$, while the coupling reaction with aryl bromides required temperatures over $95^{\circ} \mathrm{C}$ to reach complete conversion. For less reactive sodium benzenesulfinate, aryl iodides gave complete conversion at $90^{\circ} \mathrm{C}$, while aryl bromide led to incomplete conversion even at $95^{\circ} \mathrm{C}$. ${ }^{[12]}$

L-Proline was demonstrated to be helpful for copper-catalyzed coupling of of aryl iodides, aryl bromides and phenols could be used as coupling partners (Scheme

and aryl bromides at $60-90{ }^{\circ} \mathrm{C}$ to provide heterocycles include substituted ind

of amino acids could facilitate copperto be the best ligand for this biaryl ether formation. ${ }^{[8]}$ In this case, the coupling reaction worked well at $90{ }^{\circ} \mathrm{C}$ in dioxane using $\mathrm{Cs}_{2} \mathrm{CO}_{3}$ as a base, and a wide ran

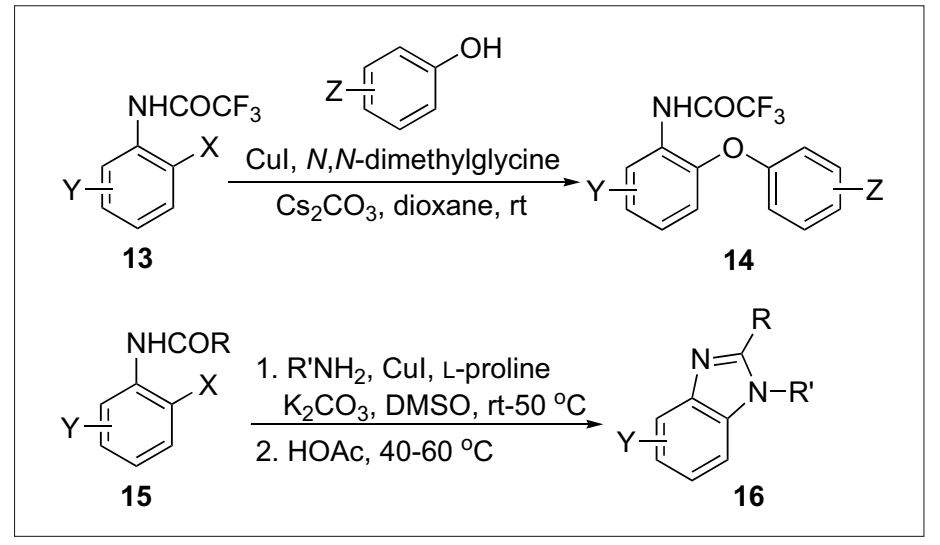

Scheme 6. Room temperature biaryl ether formation and synthesis of 1,2-disubstituted benzimidazoles. 


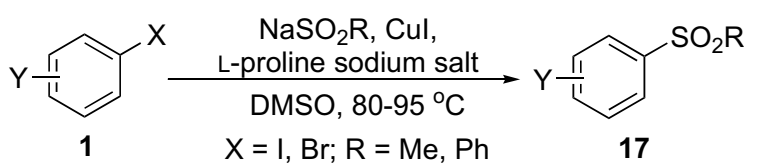

Scheme 7. Elaboration of aryl sulfones by coupling of aryl halides with sulfinic acid salts.

$$
\text { (2) }
$$

Scheme 9. Cul/amino acid-catalyzed arylation of activated methylene compounds.

aryl halides with sodium azide (Scheme 8). [13] When aryl iodides were employed, the coupling reaction worked at $40-70{ }^{\circ} \mathrm{C}$ in DMSO. In the case of aryl bromides, EtOH/ water was a suitable reaction medium, and reaction was completed at $95^{\circ} \mathrm{C}$.

The arylation of activated methylene compounds could be carried out at 40 $50{ }^{\circ} \mathrm{C}$ in DMSO under the catalysis of CuI and L-proline (Scheme 9). ${ }^{[14]}$ Both $\beta$-keto esters and malonates are suitable coupling partners, giving the arylation products in good to excellent yields. When 2-halotrifluoroacetanilides were utilized, the coupling reaction even worked at -45 ${ }^{\circ} \mathrm{C},{ }^{[15]}$ which represents a new record low in reaction temperatures for Ullmann-type coupling reactions. Asymmetric induction could be achieved during the coupling of 2-halotrifluoroacetanilides with 2-methyl acetoacetates. In this case trans-4hydroxy-L-proline gave better asymmetric induction than L-proline.

Amino acids were found to be the able to promote the CuI-catalyzed crosscoupling of aryl halides with 1-alkynes, and $N, N$-dimethylglycine was selected for further investigations. Under the catalysis of $\mathrm{CuI}$ and $N, N$-dimethylglycine, reaction proceeded at $100{ }^{\circ} \mathrm{C}$ to provide aryl acetylenes with good to excellent yields. Both aryl iodides and bromides could be used as the coupling partners, although the latter required increasing catalytic loading to $20 \% \mathrm{CuI}$ (Scheme 10).[16] This less expensive catalytic system may find usage in large scale production of aryl acetylene intermediates.

Our proposed mechanism for copper/ amino acid catalyzed coupling reactions is shown in Scheme 11. The complex A might undergo oxidative addition with aryl halides to afford complex $\mathrm{B}$, which might go through ligand exchange to deliver complex C. Reductive elimination of $\mathrm{C}$ would provide the coupling product. The complex of $\mathrm{Cu}(\mathrm{I})$ and an amino acid leads to a $\mathrm{Cu}(\mathrm{I})$ species more reactive toward oxidative addition, or/and stabilize

the oxidative addition intermediates B, thereby promoting the coupling reaction.

\section{Applications in Large-scale Production}

After the above results were disclosed, our reactions have found more than 300 applications in organic synthesis. Herein, we introduce seven examples that are used for large scale production.

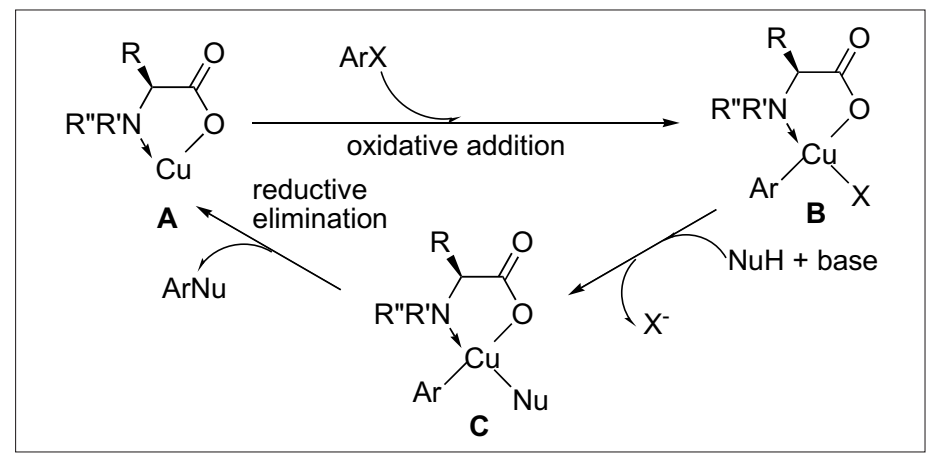

Scheme 11. Possible catalytic cycle for amino acid-promoted coupling reactions.



23<smiles>CCOC(=O)C(CCc1ccccc1)N[C@@H](C)C(=O)N1[C@H](C(=O)O)C[C@@H]2CCCC[C@H]21</smiles><smiles>O=C(O)[C@H]1Cc2ccccc2N1</smiles>

25

Indolapril<smiles>CCCC(NC(C)C(=O)N1[C@H](C(=O)O)C[C@@H]2CCCC[C@H]21)C(=O)OCC</smiles>

Perindopril
Scheme 12. Production of (S)-2indolinecarboxylic acid by combining biocatalysis and homogeneous catalysis. 
$\mathrm{Cl}$<smiles>O=C(O)Cc1cc(I)ccc1Br</smiles>
$\mathrm{H}_{2} \mathrm{~N} \underset{\mathrm{CO}_{2} \mathrm{H}}{\stackrel{140^{\circ} \mathrm{C}, 3 \mathrm{~h}}{>4 \mathrm{~kg} \mathrm{scale}}}$

Me<smiles>CCC(C(N)=O)N1CCCC1=O</smiles>

27

1. $\mathrm{HCl}$

2. $\mathrm{NaHCO}_{3}$

3. Crystallization

$60 \%$ yield
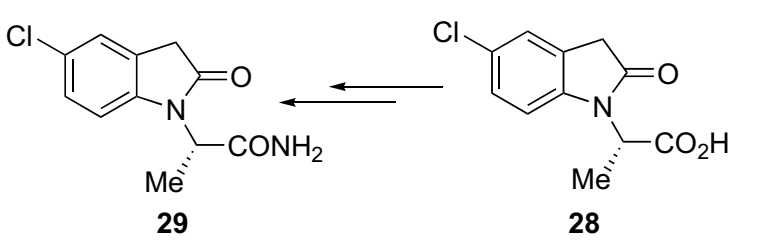

Scheme 13. Synthesis of an anti-epilepsy agent.

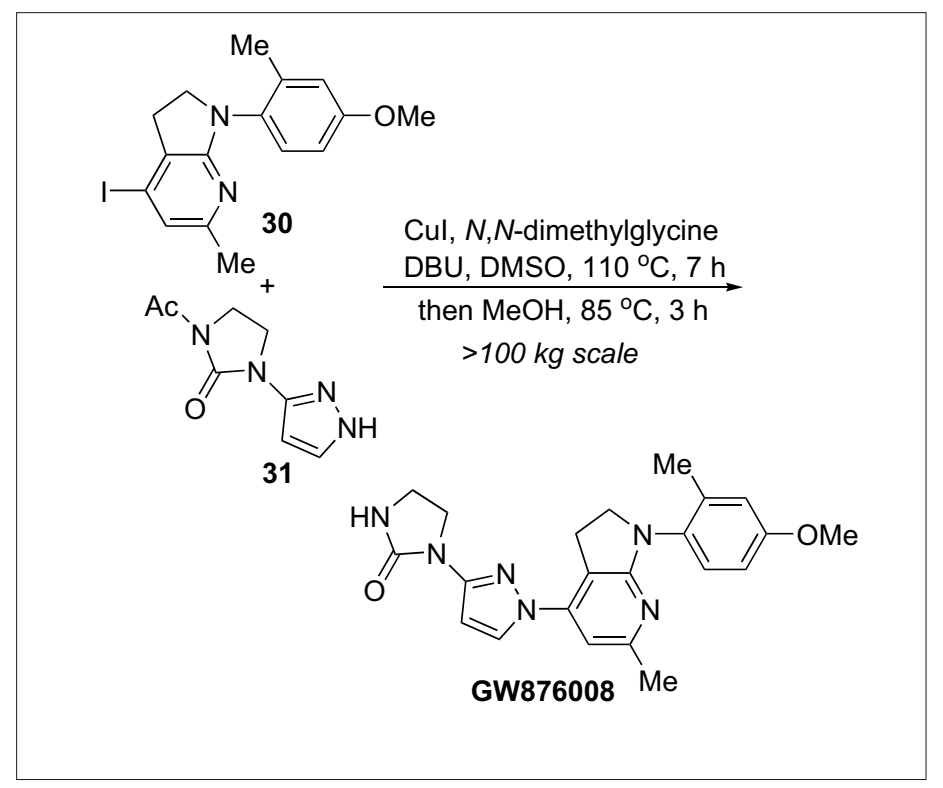

Scheme 14. Cul/ $N, N$-dimethylglycine-catalyzed coupling reaction for production of GW876008.
(S)-2-Indolinecarboxylic acid (25, Scheme 12) is a key intermediate for preparing Indolapril and Perindopril, two ACE inhibitors that are used for treatment of hypertension. Stimulated by our reports on accelerating effect of amino acids to aryl amination, DSM researchers have developed a new procedure for assembling 25 by combining biocatalysis and homogeneous catalysis. The first step is a phenylalanine ammonia lyase catalyzed enantioselective addition of ammonia to cinnamates $\mathbf{2 3}$ to deliver ortho-halophenylalanine derivatives 24 . The second step is a CuCl-catalyzed intramolecular aryl amination of 24, which proceeds smoothly in $\mathrm{H}_{2} \mathrm{O}$ at about $100{ }^{\circ} \mathrm{C}$ to provide 25 with $77 \%(\mathrm{X}=\mathrm{Br})$ and $60 \%$ $(\mathrm{X}=\mathrm{Cl})$ yields. No racemization occurred during the $\mathrm{CuCl}$-catalyzed coupling reaction. This procedure is currently used for ton-scale production by DSM Pharma Chemicals. ${ }^{[17]}$

The compound 29 is a new drug candidate developed by UCB Pharma based on the structure of Levetiracetam, a clinically used drug for treatment of epilepsy. After screening several possible routes for producing this compound in large scale, they found that a coupling protocol is scalable. As indicated in Scheme 13, CuI-catalyzed aryl amination between aryl bromide $\mathbf{2 6}$ and $(S)$-alanine completed at $140{ }^{\circ} \mathrm{C}$ after 3 h, affording $N$-aryl amino acid 27. Without purification, this acid was subjected to intramolecular condensation to give oxindole 28 with $60 \%$ yield after recrystallization. Further amidation of $\mathbf{2 8}$ provided $\mathbf{2 9}$. More than $4 \mathrm{~kg}$ of $\mathbf{2 9}$ have been produced using this procedure for preclinical toxicological studies. ${ }^{[18]}$

GW876008 is a novel corticotrophin releasing factor (CRF) antagonist that has entered phase II clinical trials for treatment of stress-related illnesses like anxiety and depression. A manufacturing synthetic route $(>100 \mathrm{~kg})$ for this compound was reported by GSK researchers recently, which is highly reliant on a $\mathrm{CuI} / N, N$ dimethylglycine catalyzed coupling reaction of aryl iodide $\mathbf{3 0}$ with pyrazolyl compound 31 (Scheme 14). A number of ligands have been examined for this transformation, and $N, N$-dimethylglycine was identified as the best one because it was less expensive and afforded the coupling product with the highest purity. Noteworthy is that in this study $\mathrm{N}, \mathrm{N}$ dimethylglycine was also used as a cheap and readily available scavenger to solve the problem of the clinical grade DS copper contamination. [19]

$D G-051$ is a first-in-class small molecule inhibitor of leukotriene A4 hydrolase $(\mathrm{LTA} 4 \mathrm{H})$ that was discovered by
deCODE Chemistry, Inc. This compound has entered Phase II clinical trials for the prevention of heart attack. A convergent four-step manufacturing sequence has been developed to produce this compound at $100 \mathrm{~kg}$ scale (Scheme 15). In this route $\mathrm{CuI} / N, N$-dimethylglycine-catalyzed biaryl ether formation was set up as the first step, which delivered phenol 33 with $68 \%$ overall yield, after demethylation with TMSI generated in situ from TMSCl and NaI.[20]

Asenapine is a clinically used drug for treatment of schizophrenia that was approved by FDA in 2009. In their process patent, [21] Organon chemists described a scalable procedure to prepare this drug. The key step is a $\mathrm{CuI} / N, N$ dimethylglycine-catalyzed intramolecular birayl ether formation of $\mathbf{3 4}$. The resultant coupling product $\mathbf{3 5}$ was transformed into Asenapine after simple deprotection and methylation (Scheme 16).

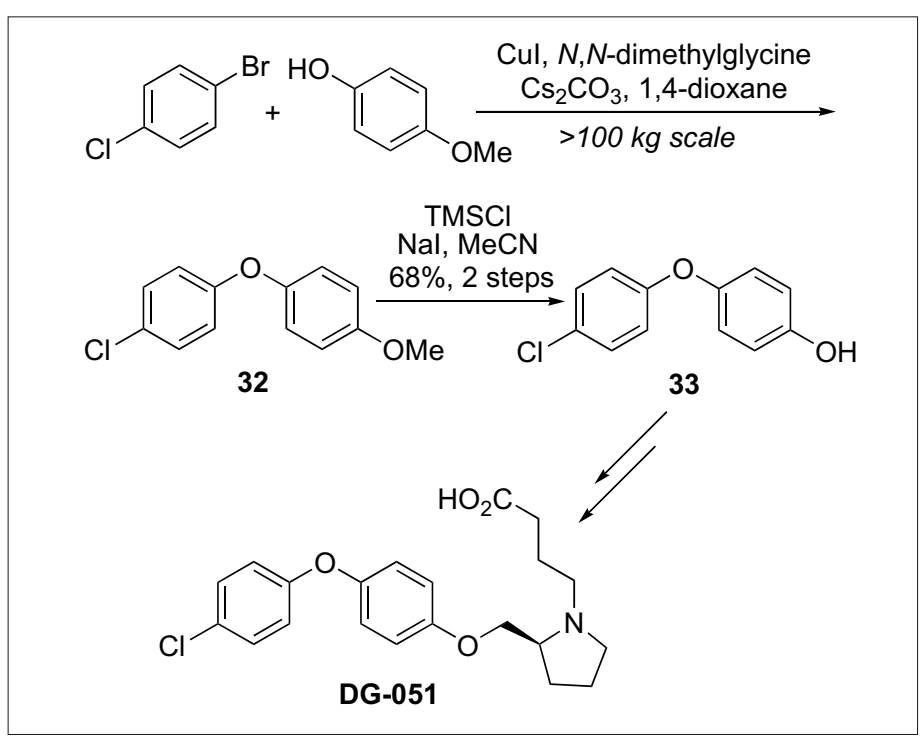

Scheme 15. Cul/N, $\mathrm{N}$-dimethylglycinecatalyzed coupling reaction for production of DG-051. 

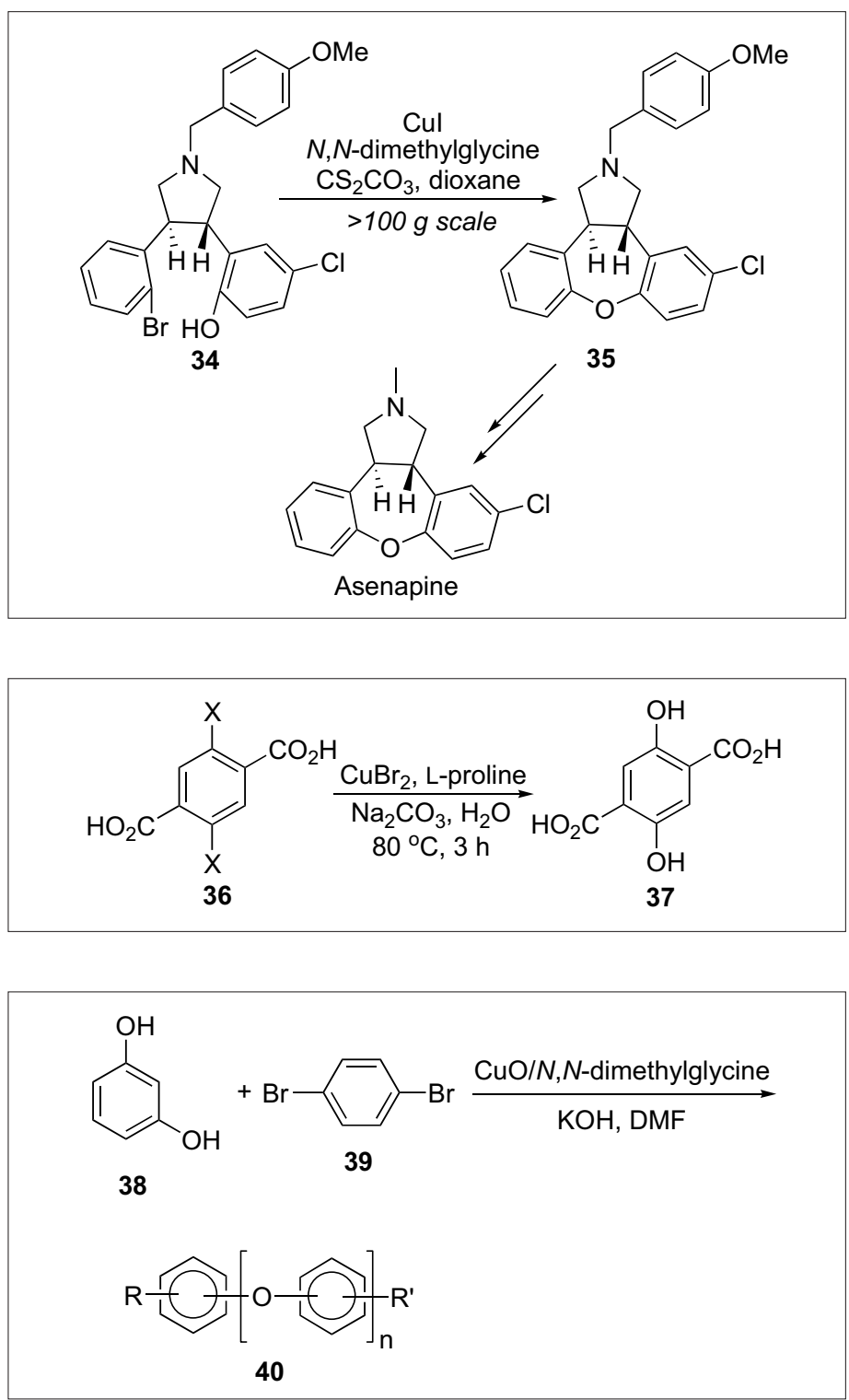

Scheme 18. Cul/N, $\mathrm{N}$-dimethylglycinecatalyzed polymerization.

[5] J. Kim, S. Chang, Chem. Commun. 2008, 3052.

[6] L. Jiang, X. Lu, H. Zhang, Y. Jiang, D. Ma, J. Org. Chem. 2009, 74, 4542.

[7] D. Ma, Q. Cai, Synlett, 2004, 128.

[8] D. Ma, Q. Cai, Org. Lett. 2003, 5, 3799.

[9] Q. Cai, G. He, D. Ma, J. Org. Chem. 2006, 71, 5268.

[10] Q. Cai, B. Zou, D. Ma, Angew. Chem., Int. Ed. 2006, 45, 1276.

[11] B. Zou, Q. Yuan, D. Ma, Angew. Chem., Int. Ed. 2007, 46, 2598 .

[12] W. Zhu, D. Ma, J. Org. Chem. 2005, 70, 2696

[13] W. Zhu, D. Ma, Chem. Commun. 2004, 888.

[14] X. Xie, G. Cai, D. Ma, Org. Lett. 2005, 7, 4693.

[15] X. Xie, Y. Chen, D. Ma, J. Am. Chem. Soc. 2006, 128, 16050.

[16] D. Ma, F. Liu, Chem. Commun. 2004, 1934

[17] B. Lange, D. J. Hyett, P. J. D. Maas, D. Mink, F. B. J. Assema, N. Sereinig, A. H. M. Vries, J. G. Vries, ChemCatChem 2011, 3, 289.

[18] F. Broeders, L. Defrère, M.-F. Deltent, F. Driessents, F. Gilson, L. Grooters, X. Ikonomakos, F. Limauge, E. Sergeef, N. Verstraeten, Org. Proc. Res. Dev. 2009, 13, 442.

Scheme 17. Cul/ L-proline-catalyzed hydroxylation of aryl halides.

[19] A. Ribecai, S. Bacchi, M. Delpogetto, S. Guelfi, A. M. Manzo, A. Perboni, P. Stabile, P. Westerduin, M. Hourdin, S. Rossi, S. Provera, L. Turco, Org. Proc. Res. Dev. 2010, 14, 895.

[20] L. A. Enache, I. Kennedy, D. W. Sullins, W. Chen, D. Ristic, G. L. Stahl, S. Dzekhtser, R. A. Erichson, C. Yan, F. W. Muellner, M. D. Krohn, J. Winger, V. Sandanayaka, J. Singh, D. E. Zembower, A. S. Kiselyov. Org. Proc. Res. Dev. 2009, 13, 1177.

[21] G. J. Kemperman, T. L. Stuk, J. J. M. Linden, US20100234618.

[22] J. C. Ritter, US7553990.

[23] L. D. Timberlake, J. A. Mckeown, WO2011014316
2,5-Dihydroxyterephthalic acid (37) is a useful monomer for the synthesis of high strength fibers such as those made from poly [(1,4-dihydrodiimidazo[4,5-b:4'5'-e] pyridine-2,6-diyl)(2,5-dihydroxy-1,4phenylene)]. In a recent patent, Ritter from E.I. du Pont reported a new procedure for preparing this acid, which is dependent on $\mathrm{CuBr}_{2} / \mathrm{L}$-proline-catalyzed hydroxylation of 2,5-dihaloterephthalic acid 36. The reaction gave $100 \%$ conversion in water at $80{ }^{\circ} \mathrm{C}$ after $3 \mathrm{~h}$, while no reaction occurred if L-proline was absent (Scheme 17). ${ }^{\text {[2] }}$

Aryl ether oligomer 40 is the precursor for preparing flame retardant halogenated aryl ether oligomer. Its production could be achieved by $\mathrm{CuO} / \mathrm{N}, \mathrm{N}$-dimethylglycinecatalyzed polymerization of resorcinol (38) and 1,4-dibromobenzene (39) (Scheme 18). Among the ligands examined, $N, N$ dimethylglycine showed the best performance for this reaction. [23]

In conclusion, we have demonstrated that a number of copper-catalyzed cross coupling reactions of aryl halides and nucleophiles could be promoted by choosing L-proline, 4-hydroxy-L-proline or $N, N$-dimethylglycine as ligands. The newly developed catalytic systems enabled coupling reactions under mild conditions. The amino acids' relative inexpensiveness and their facile removal from reaction mixtures make these reactions very attractive for large-scale synthesis, as demonstrated by seven application examples.

Received: September 25, 2011

[1] For selected reviews, see: a) S. V. Ley, A. W Thomas, Angew. Chem., Int. Ed. 2003, 42, 5400 ; b) I. P. Beletskaya, A. V. Cheprakov, Coord. Chem. Rev. 2004, 248, 2337; c) G Evano, N. Blanchard, M. Toumi, Chem. Rev. 2008, 108, 3054; d) D. Ma, Q. Cai, Acc. Chem. Res. 2008, 41, 1450. e) F. Monnier, M. Taillefer, Angew. Chem., Int. Ed. 2009, 48, 6954; f) D. S. Surry, S. L. Buchwald, Chem. Sci. 2010, 13.

[2] D. Ma, Y. Zhang, J. Yao, S. Wu, F. Tao, J. Am. Chem. Soc. 1998, 120, 12459.

[3] D. Ma, Q. Cai, H. Zhang, Org. Lett. 2003, 5, 2453.

[4] H. Zhang, Q. Cai, D. Ma, J. Org. Chem. 2005, 70,5164 . 